\title{
Motor Axon Guidance of the Mammalian Trochlear and Phrenic Nerves: Dependence on the Netrin Receptor Unc5c and Modifier Loci
}

\author{
Robert W. Burgess, ${ }^{1}$ Thomas J. Jucius, ${ }^{1}$ and Susan L. Ackerman ${ }^{1,2}$ \\ ${ }^{1}$ The Jackson Laboratory and ${ }^{2}$ Howard Hughes Medical Institute, Bar Harbor, Maine 04609
}

\begin{abstract}
Netrin signaling is important to guide migrating neurons and axons in many systems. Experiments with vertebrate CNS explants suggested netrin is bifunctional, attracting some axons and repelling others. Netrin1-expressing cells attracted spinal commissural axons and repelled trochlear cranial nerve axons in these experiments. Subsequent genetic studies demonstrated that multiple axon types, including those of the spinal commissural neurons, are attracted to netrin in vivo; however, an in vivo role for netrin signaling in trochlear nerve repulsion has not been observed. Here, we demonstrate that mice with a null mutation in the netrin receptor Unc $5 c$ on the inbred C57BL/6J (B6) genetic background have ventral/ipsilateral trochlear nerve misprojections. These misprojections are attenuated on a hybrid B6 $\times$ SJL background. In addition, B6.Unc5c $c^{-1-}$ mice die as neonates of apparent respiratory distress and have incomplete phrenic nerve innervation of the diaphragm muscle. Neither the trochlear nerve misprojections nor the phrenic nerve phenotype was observed in B6 embryos lacking the netrin receptors DCC or Neogenin1, or the ligand netrin1, indicating these signaling molecules are dispensable for guidance of these axons. Like the trochlear nerve, the phrenic nerve phenotype is modified in a B6 $\times$ SJL hybrid background. To identify these modifier loci, we performed genome scans of the hybrid $U n c 5 c^{-1-}$ mice and found a major SJL-derived suppressor locus on Chromosome 17. Our results provide the first evidence that genes involved in netrin signaling are necessary for proper mammalian spinal motor axon development and trochlear axon guidance. In addition, they demonstrate the importance of modifier genes in vertebrate axonal guidance.
\end{abstract}

Key words: rcm; Unc5h3; genetic background; modifier gene; QTL; mouse; ophthalmic; trigeminal

\section{Introduction}

Motor neuron axons find their target muscle using a variety of molecular cues that result in either attraction toward their targets or repulsion away from nontarget cells (Schneider and Granato, 2003). Peripheral axon guidance has been studied extensively in invertebrates. In Caenorhabditis elegans, the ligand UNC-6 (netrins in vertebrates) is both a chemoattractant and chemorepellent. Cells expressing the receptor UNC-40 (DCC and neogenin in vertebrates) are attracted to UNC-6 (Chan et al., 1996), whereas cells expressing UNC-5 (Unc5A-D in vertebrates) are repelled (Hedgecock et al., 1987, 1990; Wadsworth and Hedgecock, 1996; Wadsworth et al., 1996). Studies on Drosophila netrin-signaling mutations demonstrate that specific motor axon populations misproject after exiting the CNS (Kolodziej et al., 1996; Mitchell et al., 1996; Labrador et al., 2005). Netrin signaling

Received Aug. 25, 2005; revised April 14, 2006; accepted April 17, 2006.

This work was supported by grants from the Edward Mallinckrodt Jr. Foundation (R.W.B.) and the National Institutes of Health (NS35900 to S.L.A.). S.L.A. is an investigator of the Howard Hughes Medical Institute. We thank the scientific services at The Jackson Laboratory, in particular Doug McMinimy in the Allele Typing Service; Pete Finger, Greg Martin, and Dr. Jim Denegre in the Bioimaging Service; and Weidong Zhang in the Computational Biology Service. We thank Dr. Steven Rauch for assistance in quantitative PCR, Dr. Tom Gridley for comments on this manuscript, and Dr. Wayne Frankel for statistical assistance.

Correspondence should be addressed to Dr. Susan L. Ackerman, The Jackson Laboratory, 600 Main Street, Bar Harbor, ME 04609. E-mail: susan.ackerman@jax.org.

DOI:10.1523/JNEUROSCI.0736-06.2006

Copyright $\odot 2006$ Society for Neuroscience $\quad$ 0270-6474/06/265756-11\$15.00/0 regulates cell migration and axon pathfinding of several cell types in vertebrates (Barallobre et al., 2005), but a role for netrin signaling has not been demonstrated in vivo in motor axons.

In vertebrates, cranial and spinal motor neurons lie in a ventral column, lateral to the netrin1-expressing floor plate. Spinal motor axons initially project ventrally away from the midline. Other axons, including several cranial nerves, extend dorsally, growing through the neuroepithelium before exiting the CNS near the midpoint of the alar plate. Explant studies indicate that netrin 1 contributes to the guidance of motor axons; however, subpopulations of these axons differ in their netrin response in vitro. Netrin repels dorsally projecting cranial motor axons from the trochlear, trigeminal, facial, glossopharyngeal, and vagus nuclei (cranial nerves IV, V, VII, IX, and X, respectively), but no netrin response is elicited in ventrally projecting spinal motor axons (Colamarino and Tessier-Lavigne, 1995; Shirasaki et al., 1996; Varela-Echavarria et al., 1997). Additional signals have been identified that may repel dorsally projecting cranial motor axons from the ventral brainstem (Varela-Echavarria et al., 1997; Chen et al., 2000; Giger et al., 2000), possibly explaining the normal projection of these axons in netrin 1 mutant mice.

Mice homozygous for the rostral cerebellar malformation $(\mathrm{rcm})$ mutation, a null mutation in the netrin receptor $U n c 5 c$, have numerous CNS phenotypes, including cerebellar hypoplasia, granule and Purkinje cell mismigration, and defects in corti- 
cospinal tract (CST) pathfinding (Ackerman et al., 1997; Przyborski et al., 1998; Goldowitz et al., 2000; Finger et al., 2002). Here, we show that mutation of $U n c 5 c$ also disrupts the development of specific motor axons. Furthermore, the genetic background of the $U n c 5 c$ mutant mice modulates this phenotype. $U n c 5 c^{-/-}$mice in a hybrid genetic background live a normal life span; however, mutant mice on a C57BL/6J (B6) inbred background die perinatally of apparent respiratory distress. A misprojection of axons in the trochlear nerve was observed in early embryonic ages, and a paucity of motor innervation of the diaphragm by the developing phrenic nerve was seen in later-stage embryos. Netrin 1 and the UNC-40-related receptors DCC and neogenin are dispensible for guidance of the trochlear and phrenic nerves, as demonstrated by the lack of motor axon defects in mice lacking these components of the netrin-signaling pathway. In addition, the SJL/J genetic background has a major modifier locus that suppresses the phrenic phenotype of B6.Unc5c mutant embryos.

\section{Materials and Methods}

Mice. B6.cg-Unc5 $c^{r c m T g(U c p) 1.23 \mathrm{Kz} / \text { Slac }}$ mice (hereafter referred as B6.Unc5c) were generated by repeated backcrossing of $U n c 5 c^{+/-}$animals to C57BL/6J (B6) for at least 28 generations. B6.129Ntn1 ${ }^{\text {Gt(pGT1.8TM)629Wcs }}$ (B6.Ntn1), B6.129S2-Dcc ${ }^{\text {tm1 Wbg }}$ (B6.Dcc), and B6.129-Neo1 (B6.Neo1) gene-trap mice were crossed to B6 for a minimum of 24, 20, and 5 generations, respectively. In some experiments, motor axons were visualized by crossing the enhanced yellow fluorescence protein (EYFP) motor-neuron-reporter line B6.cg-(Thy1YFP) 16Jrs/J (Feng et al., 2000) (backcrossed to B6 for $>10$ generations) to $U n c 5 c^{+/-}$mice. $D c c^{-/-}$and Thyl-YFP mice were identified as reported previously (Feng et al., 2000; Finger et al., 2002). Ntn1 ${ }^{-1-}$ were genotyped as described previously in embryonic day 18.5 (E18.5) embryos (Finger et al., 2002) and by quantitative PCR for the Neo gene in DNA prepared from the yolk sac of E11.5 embryos. The insertion site of the B-geo/PLAP secretory gene-trap vector (Leighton et al., 2001; Mitchell et al., 2001) into intron 19 of the neogenin gene was identified by Southern and PCR analysis, allowing design of PCR primers for genotype analysis. The primer pair WtF (CTGTCTGGGAGAAAAAGATTGC) and WtR (GGGAGGGAAAAAGGGAGTG) was used to identify the wild-type allele, and MutF (GGGTCTCTTTGTCAGGGTCAC) and MutR (GCTCTTTTCAGTAGGCTCTCTGC) amplified the mutant allele.

$U n c 5 c^{-1-}$ embryos were generated by timed matings of B6.Unc5c $c^{+/-}$ or F1 $U n c 5 c^{+/-}$mice from a B6.Unc5c ${ }^{+/-} \times$SJL/J cross. Mating was inferred from the presence of a vaginal plug (designated E0.5), at which time females were segregated from males until embryos were collected.

Immunofluorescence. For whole-mount nerve and muscle immunostaining or EYFP visualization, tissue was dissected and fixed for $2 \mathrm{~h}$ in cold $2 \%$ paraformaldehyde/PBS. Staining was performed as described previously (Gautam et al., 1996). Nerves and synaptic vesicles were visualized using mouse anti-neurofilament antibodies (165 kDa, 1:20, clone 2H3; Developmental Studies Hybridoma Bank, Iowa City, IA) and mouse anti-SV2 monoclonal antibodies (1:20; Developmental Studies Hybridoma Bank), except in Figure 5, in which rabbit antineurofilament antibodies (200 kDa, 1:300; Sigma, St. Louis, MO) and rabbit anti-synaptophysin (1:300; Zymed, San Francisco, CA) were used. Staining was visualized with goat anti-mouse IgG1 (Molecular Probes, Eugene, OR) or Alexa 488-conjugated goat anti-rabbit IgG (see Fig. 5) secondary antibodies. Acetylcholine receptors (AchRs) were visualized by staining with tetramethyl-rhodamine-conjugated $\alpha$-bungarotoxin (1: 1000; Molecular Probes). Samples were examined on a Nikon (Tokyo, Japan) fluorescence microscope, and images were collected using a SPOT 9000 camera or a Leica (Nussloch, Germany) NT confocal microscope.

Peripherin staining was done on serial cryostat sections through the midbrain and hindbrain of E18.5 mice. Approximately 80 serial $15 \mu \mathrm{m}$ sections were collected from each sample to ensure the inclusion of the trochlear nucleus. Staining was performed using standard immunofluorescence techniques, using anti-peripherin antibodies (Novus Biologi- cals, Littleton, CO) at a 1:400 dilution, followed by Cy3-conjugated donkey anti-rabbit antibodies.

Whole-mount embryo staining for neurofilament was performed as described previously (Kitsukawa et al., 1997). After signal visualization with $\mathrm{DAB}$, embryos were dehydrated through a methanol series and placed into methyl salicylate to clear the tissue. Images were obtained on a Leitz/Wild (Wetzlar, Germany) stereomicroscope with a Leica FX300 camera.

In situ hybridization. Digoxygenin-labeled Dcc, Neo1, and Chat riboprobes were generated by reverse transcription-PCR (RT-PCR) from total brain cDNA using the following primer sets: ChatF (GACTTACCTAAGTTGCCAGTGC), ChatR (CCTTAGCTGGTCATTGGTGTC), Neo1F (AGCTATGAACCAGATGAGCTG), NeolR (CTCCCTTGGCTTCTGATATGTG), Dcc-F (ACCAAGGTCGTCATGGAGATG), and Dcc-R (TGCTGCCAGGGACCGTTCC). To facilitate riboprobe production, a T3 promoter $5^{\prime}$ overhang (GCAATTAACCCTCACTAAAGGG) was added to each forward $\left(5^{\prime}\right)$ primer, and a T7 promoter $5^{\prime}$ overhang (GTATATCGACTCACTATAGGG) was added to each reverse $\left(3^{\prime}\right)$ primer. Antisense and sense probes were generated by in vitro transcription with T7 or T3 polymerase, respectively, directly from the PCR product. Unc5c riboprobes were generated as described previously (Ackerman et al., 1997). Serial sections through the cervical spinal cord of fresh-frozen E14.5 embryos were collected using a cryostat, and in situ hybridization was performed as described previously (Burgess et al., 2004). After hybridization, sections were incubated with peroxidaseconjugated anti-digoxygenin antibodies (1:2000; Roche Products, Welwyn Garden City, UK). Signals were amplified with the Tyramide Signal Amplification Plus kit (TSA-Plus; PerkinElmer, Wellesley, MA) as per the manufacturer's protocol, using a 1:50 dilution of tyramide substrate in reaction buffer. Signals were developed for $1 \mathrm{~h}$. Parallel control experiments using sense-strand probes did not reveal any signals above background.

Axon counts. To determine axon numbers, left and right phrenic nerves were isolated from E18.5 or P0 mice in 2\% glutaraldehyde and $2 \%$ PFA in $0.1 \mathrm{~m}$ cacodylate buffer. Nerves were postfixed for $4 \mathrm{~h}$ in the same fixative before processing for plastic embedding and transmission electron microscopy (TEM). Sections $(0.5 \mu \mathrm{m})$ were also stained with toluidine blue and examined by light microscopy. TEM images were collected at $5000 \times$ magnification on a JEOL (Peabody, MA) 1230 microscope.

Genome scans. DNA for genome scan analysis was prepared from tail or liver samples using a PureGene DNA isolation kit (Gentra Systems, Minneapolis, MN). PCRs using fluorochrome-labeled microsatellite simple sequence length polymorphism markers were run using an $\mathrm{ABI}$ 3700 , and the resulting data were analyzed using Genescan and Genotyper software (Applied Biosystems, Piscataway, NJ).

Quantitative trait loci (QTL) main effects were determined as described previously (Sen and Churchill, 2001) using the R/qtl version 0.98-57 program (Broman et al., 2003) (http://www.biostat.jhsph.edu/ $\sim \mathrm{kbroman} /$ software/). Multiple imputations are used in this method to generate genotypes on a regular grid of genome-wide locations conditional on the observed marker data. The logarithm of the odds (LOD) score for each marker location was calculated by averaging the LOD scores over imputations. A whole-genome scan was performed at 2 centimorgan (cM) spacing using 128 imputations for the phenotype considering single QTL for each chromosome. One thousand permutations of the phenotype values were used to determine $5 \%$ and $1 \%$ threshold values (Churchill and Doerge, 1994), which correspond the red and green lines in the mainscan plot.

\section{Results}

\section{The Unc5c mutation is lethal on a C57BL/6 background}

The $U n c 5 c$ gene was identified by molecular characterization of mice with cerebellar defects attributable to insertion of an unrelated transgene into the Unc5c locus (Ackerman et al., 1997). Insertion of this transgene was accompanied by the deletion of Unc5c exons and complete loss of Unc5c transcripts in mice homozygous for the transgene. Despite their severe ataxia, mutant mice have a normal life span on the original C57BL/6J $\times \mathrm{SJL} / \mathrm{J}$ segregating background. 
Table 1. Perinatal lethality of Unc5 $\mathrm{c}^{-1-}$ mice on the $\mathrm{C57BL} / 6 \mathrm{~J}$ background

\begin{tabular}{lllc}
\hline & Unc5c $^{+/+}$ & Unc5c $^{+/-}$ & Unc5c $^{-/-}$ \\
\hline B6 congenic $^{a}$ & $20(29 \%)$ & $48(71 \%)$ & 0 \\
F2 B6/SJL $^{b}$ & $16(27 \%)$ & $32(54 \%)$ & $11(19 \%)$
\end{tabular}

Mice heterozygous for the Unc $5 \mathrm{c}$ mutation were bred to $(57 \mathrm{BL} / 6 \mathrm{~J}$ (B6) mice for 10 generations to create the congenic line B6.Unc5c. B6.Unc5 $\mathrm{C}^{+/-}$mice were intercrossed, and resulting offspring were examined for ataxia and genotyped. Alternatively, $\mathrm{B} 6 . U n \mathrm{CC}^{+/-}$mice were mated to $\mathrm{SJL} / \mathrm{J}$ mice to create $\mathrm{F} 1 \mathrm{UnC}_{\mathrm{CC}} \mathrm{C}^{+/-}$mice, which were intercrossed to generate $F 2$ mice on a segregating $B 6 / S J L$ background. The number of mice for each genotype surviving to 3 weeks is shown for each cross.

${ }^{a} \chi^{2}=19.63 ; p<0.001$.

${ }^{b} \chi^{2}=0.69 ; p<1.0$.

A dramatic decrease in the number of mutant animals surviving until weaning was found when this $U n c 5 c$ mutant allele was transferred to a C57BL/6J (B6) inbred background. This increase in mortality was evident by the third backcross generation (N3), and by the N10 generation (in which $>99 \%$ of unlinked loci should be derived from B6), no $U n c 5 c^{-1-}$ mice were observed at 3 weeks of age in the 68 mice examined (Table 1). In contrast, 11 of 59 mice (19\%) were homozygous for the Unc5c mutation from an intercross of F1 B6/SJL heterozygotes. This increase in lethality of the $U n c 5 c$ mutants on an inbred B6 background suggested that loci from the $\mathrm{B} 6$ genetic background are capable of modifying the mutant phenotype.

\section{Trochlear nerve defects in B6.Unc5 $c^{-/-}$mice}

To look for additional neurodevelopmental defects that may arise in the B6 background to shorten the life span, we performed whole-mount neurofilament immunohistochemistry on E11.5 embryos. Grossly, axon outgrowth and projections appeared normal, even in B6.Unc5c $c^{-/-}$mice (Fig. $1 A, B$ ). However, striking misprojections of the trochlear nerve were seen in mutant embryos (Fig. $1 B$ ).

In control mice, the trochlear nerve projects dorsally from the trochlear nucleus located in the caudal midbrain/rostral region of rhombomere 1 and elongates along the midbrain/hindbrain boundary (Fig. 2A-D). At the dorsal midline, it crosses to exit the brainstem before turning rostroventrally to innervate the superior oblique muscle of the contralateral eye. In B6.Unc5c $c^{-1-}$ mice, the trochlear nerve initially projects ventrally rather than dorsally and exits the CNS ipsilaterally rather than decussating. The phenotype was variable from embryo to embryo, and not all axons of the trochlear nerve misproject (Table 2); however, every B6.Unc $5 c^{-/-}$mouse examined had clear abnormalities in at least one trochlear nerve $(n=6)$. The misprojection is most evident in cases such as Figure $2 E-H$, where the right side of the embryo has two trochlear nerves (Fig. $2 E$ ), one arising from the left trochlear nucleus and decussating as it should (Fig. $2 F$ ), whereas the nerve arising from the right trochlear nucleus exits ventrally on the ipsilateral side. As a result, there is no trochlear nerve on the left side of the embryo (Fig. $2 G$ ). In other cases, both the left and right nerve make almost entirely ventral projections (Fig. $2 I-L$ ), or nerves on both sides of the embryos each take both dorsal and ventral trajectories (Fig. $2 M-P$ ).

Because $U n c 5 c$ is known to guide cell migration, we examined the trochlear nucleus in B6.Unc5 $c^{-/-}$mice to determine whether the misprojection of the trochlear axons was accompanied by mislocalization of the cell bodies. The trochlear nucleus lies near the midbrain/hindbrain junction behind the occulomotor nucleus and at the rostral border of the mesencephalic nucleus of cranial nerve $\mathrm{V}$. The cell bodies of the trochlear nucleus are near the midline, just ventral to the cerebral aqueduct, and can be identified by staining with peripherin (Pattyn et al., 1997; Cop-
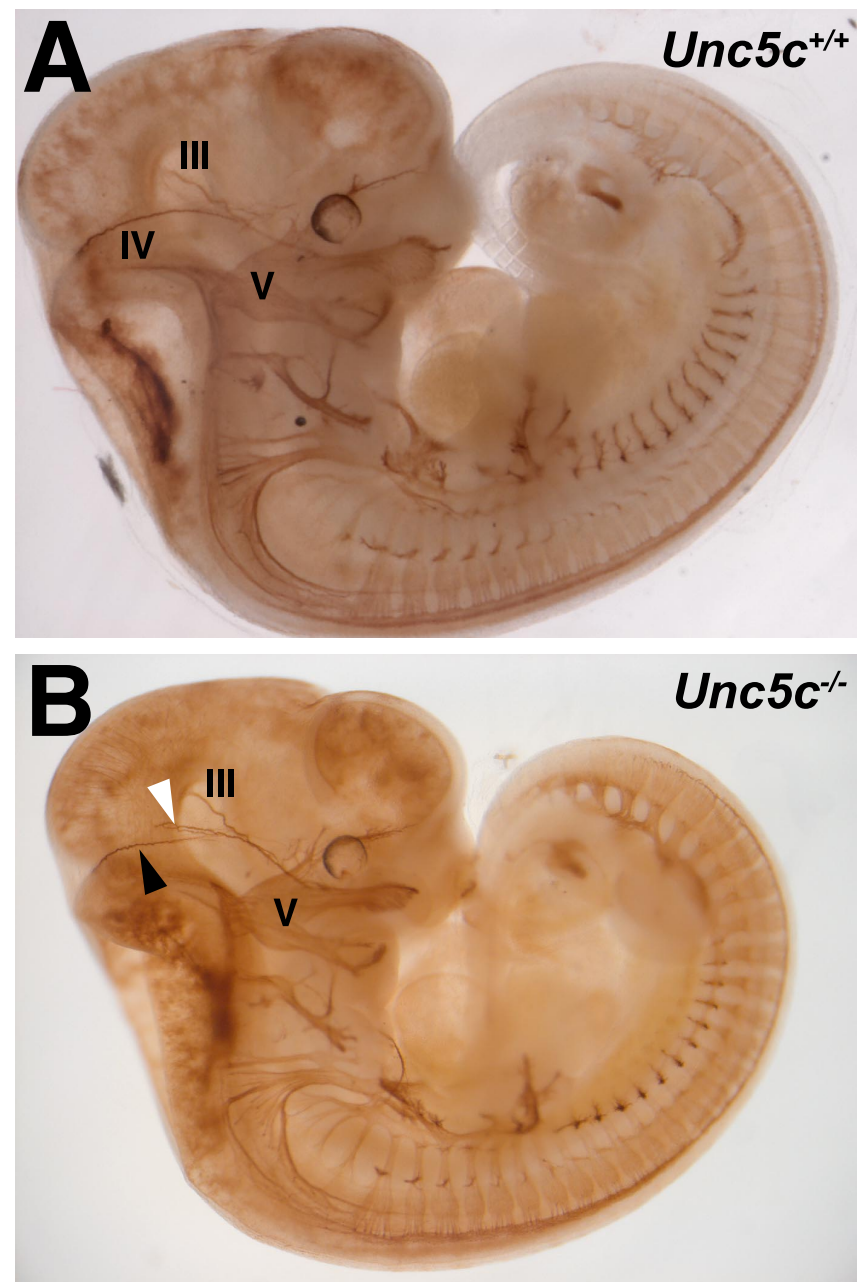

Figure 1. Trochlear nerve abnormalities in $\mathrm{B} 6 . U n \mathrm{CSC}^{-1-}$ mice. Embryos were stained for neurofilament at E11.5 to visualize developing axonal projections. Control $(\boldsymbol{A})$ and $U n \mathrm{C}^{-1 /-}$ $(\boldsymbol{B})$ embryos were grossly alike, with the exception of the trochlear nerve. The trochlear nerve (IV) arises from the dorsal brainstem midway between the oculomotor nerve (III) and the trigeminal nerve $(V)$. In mutant embryos, a nerve projecting ventrally from the caudal midbrain was evident ( $\boldsymbol{B}$, white arrowhead). Such a ventral projection was seen in every $\mathrm{B} 6 . \operatorname{Unc5\mathrm {C}^{-1-}}$ embryo examined $(n=6)$, but the phenotype was variable, and a dorsally projecting nerve was also frequently seen ( $\boldsymbol{B}$, black arrowhead).

pola et al., 2005). Analysis of E18.5 wild-type and $U n c 5 c^{-/-}$embryos ( $n=7$ control, $n=3$ mutant) revealed the nucleus to be in the correct location, with no evidence of ectopic cells (Fig. $3 A, B$ ), indicating that the misprojecting trochlear axons in mutant embryos are unlikely to be secondary to abnormal migration of trochlear neurons.

Consistent with our hypothesis that the increased phenotypic severity of the $U n c 5 c^{-1-}$ mice on the B6 inbred background affects neurodevelopment, hybrid B6 $\times$ SJL F2 mice homozygous for the $U n c 5 c$ mutation showed trochlear misprojections in only two of five homozygotes examined (Fig. $3 C-H$ ). No misprojection of trochlear axons could be seen in the other three $U n c 5 c^{-1-}$ animals, suggesting that the SJL background has genes that rescue this guidance phenotype.

\section{Other netrin signaling molecules are dispensible for trochlear guidance}

The conticospinal tract misprojections in $U n c 5 c^{-/-}$mice phenotypes partially overlap those of mice with mutations in other netrin signaling molecules, including Dcc and netrin1 (Finger et 

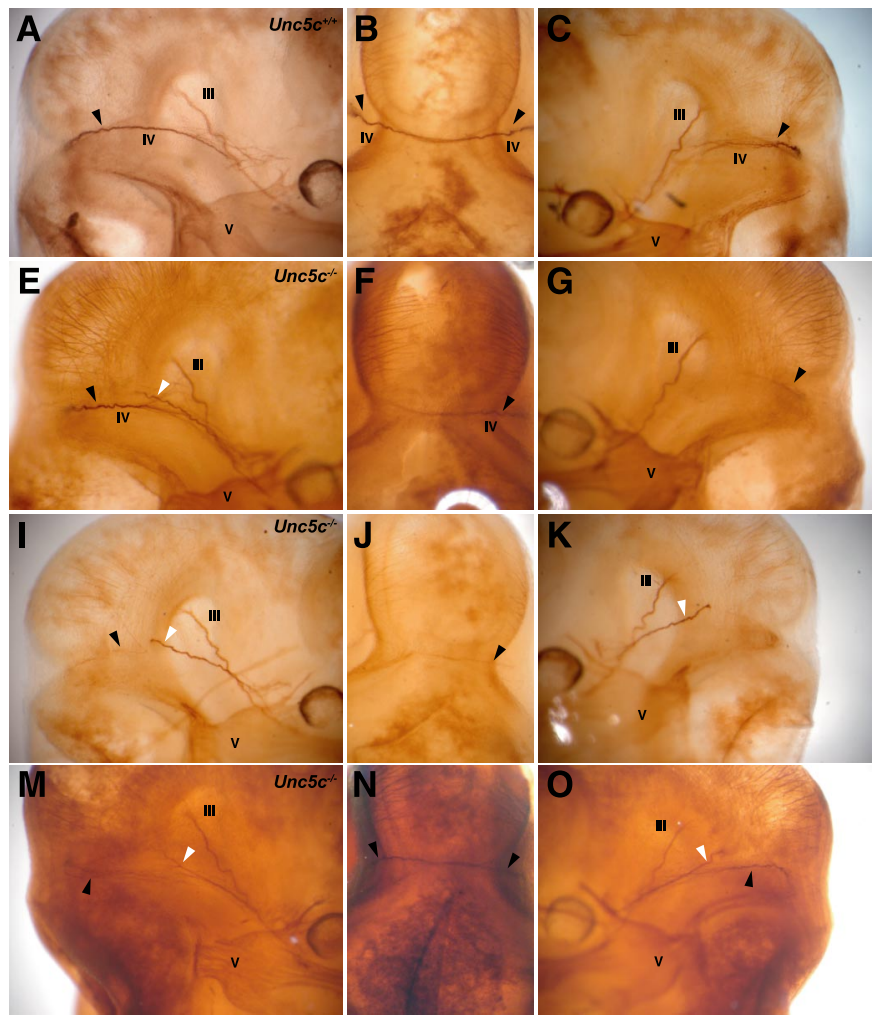

Figure 2. Trochlear axon phenotypes in $B 6 . U n c 5 C^{-1-}$ embryos. The trochlear nerve (IV) was visualized by whole-mount anti-neurofilament staining of E11.5 embryos. $\boldsymbol{A}-\boldsymbol{D}$, In a control embryo, viewed from the right $(\boldsymbol{A})$, dorsally $(\boldsymbol{B})$, and from the left $(\boldsymbol{C})$, the trochlear nerve (black arrowheads) can be seen projecting from the dorsal brainstem at the isthmus, midway between the oculomotor nerve (III) and the trigeminal nerve (V). The nerve courses toward the eye where it will innervate the contralateral superior oblique muscle. The decussation of the nerve is clearly seen in dorsal views $(\boldsymbol{B})$, and the anatomy is schematized in a coronal cross section (D), where the trochlear nerve is in red, the trochlear nucleus (IV) is in blue, and the aqueduct is noted. The

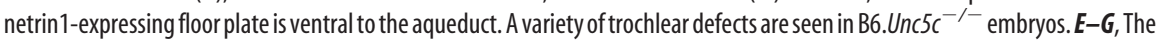
embryo has two trochlear nerves on the right $(\boldsymbol{E})$, one from the contralateral nucleus that clearly decussates correctly (black arrowheads; $\boldsymbol{E}, \boldsymbol{F}$ ) and one from the ipsilateral nucleus, which projects from the ventral CNS (white arrowhead; $\boldsymbol{E}$ ). As a result, no trochlear nerve is present on the left side of the embryo $(\boldsymbol{G})$. This is schematized in $\boldsymbol{H}$. $\boldsymbol{I}-\boldsymbol{K}$, The embryo has a trochlear nerve on each side (white arrowheads; $\boldsymbol{I}, \boldsymbol{K}$ ), but both nerves arise almost entirely from ventral projections, and only a scant decussating dorsal projection from the left side can be seen (black arrowheads; $\boldsymbol{I}, \boldsymbol{J}$ ). This is schematized in $\boldsymbol{L}$. $\boldsymbol{M}-\boldsymbol{P}$, An embryo with bilateral defects, with both normal (black arrowheads) and abnormal (white arrowheads) nerves on each side is also shown and schematized ( $\boldsymbol{P}$ ). Aq, Aqueduct.

Table 2. Axonal projections in B6.Unc5 $\mathrm{c}^{-1-}$ trochlear nerves

\begin{tabular}{lll}
\hline Genotype & Left trochlear & Right trochlear \\
\hline$+/+$ & Dorsal $(n=18)$ & Dorsal $(n=18)$ \\
$-/-\# 1$ & 0 & Dorsal and ventral \\
$-/-\# 2$ & Ventral & Ventral \\
$-/-\# 3$ & Dorsal but thin & Dorsal and ventral \\
$-/-\# 4$ & Ventral, few dorsal & Ventral \\
$-/-\# 5$ & 0 & Dorsal and ventral \\
$-/-\# 6$ & Dorsal and ventral & Dorsal and ventral
\end{tabular}

Right and left trochlear nerves in E11.5 whole-mount embryos were visualized by neurofilament antibody staining. Axonal projections were characterized as emanating from the dorsal midbrain/hindbrain boundary (the wild-type situation, noted as 'Dorsal'), or from the ventral portion of the midbrain between the occulomotor and trigeminal nerves, noted as 'Ventral.' Samples \#1 and \#5 showed a dorsal contralateral projection and a ventral ipsilateral projection on the right side of the embryo, resulting in no nerve on the left. The $n=18$ stated for the control samples represents the total number of wild-type mice examined from B6 congenic crosses of heterozygous mutants, including netrin1, DCC, and neogenin 1 crosses. No defects were observed in these embryos or in any heterozygous Unc $5 \mathrm{C}^{+/-}$embryos examined.

al., 2002). However, although netrin1 (Ntn1) has been shown to be a chemorepellent for trochlear axons in vitro, no trochlear

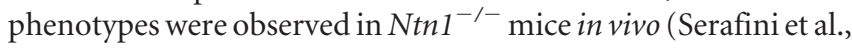
1996). Because of the dependency of this phenotype on the B6 genetic background in $U n c 5 c^{-1-}$ mice, we examined guidance of
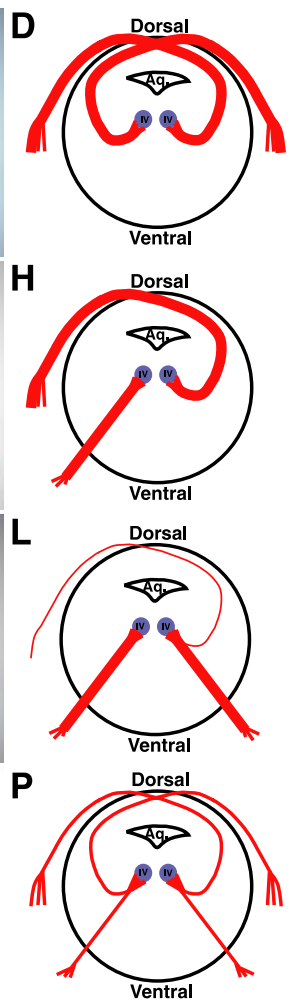

the trochlear axons in B6.Ntn1 $1^{-1-}$ embryos (Fig. $4 A, B)(n=6)$. In vitro assays have suggested UNC5 receptors act as coreceptors for DCC, modulating its netrin response from attraction to repulsion. Thus, we also examined this projection in B6.Dcc ${ }^{-/-}$embryos and embryos defective for the other UNC40 family member, neogenin1 (B6.Neo1 ${ }^{-/-}$) (Fig. 4C,D) $(n=$ 5 and 4 , respectively). No trochlear nerve defects were observed in mice with any of these mutations, although $\mathrm{NeO}^{-1-}$ mice lacked the ophthalmic branch of the developing trigeminal nerve (Fig. 4C). Although Ntn1, Dcc, and Neol may be involved in trochlear axon guidance in modulatory or redundant roles, our results show that none of these genes are solely essential for the process in vivo.

Phrenic axons defects in B6.Unc5c mice Although misprojection of the trochlear nerve is unlikely to account for neonatal lethality, these results suggested that other neurodevelopmental phenotypes may arise in $U n c 5 c^{-1-}$ embryos on the B6 background. We therefore looked for additional phenotypes in older embryos that may explain the shortened life span of Unc 5 c mutants.

We noted that some neonates in litters from the B6.Unc5c $\mathrm{c}^{+/-}$parents appeared to be gasping rather than breathing efficiently at birth, and these mice became cyanotic and died within a few hours of birth. Genotype analysis indicated these mice were homozygous for the Unc5c mutation. Histological analysis revealed the gastrointestinal tracts were distended, consistent with air gasping; however, the gross morphology of all other organs, including the palate and lungs, appeared normal (data not shown).

Neonatal respiratory distress and subsequent lethality can be associated with defects in innervation of the diaphragm and other respiratory muscles (Sanes and Lichtman, 2001; Burgess et al., 2004). To determine whether such defects occur in B6.Unc5c mutant mice, diaphragm innervation was analyzed in E18.5 mutant and littermate control embryos. To visualize the phrenic nerves, diaphragms were stained with antibodies against neurofilament and either SV2 or synaptophysin, and postsynaptic AChRs on the muscle fibers were identified by rhodamineconjugated $\alpha$-bungarotoxin.

The phrenic nerves arise bilaterally from motor neurons in the cervical spinal cord (C3-C6) (see supplemental Fig. S1 for schematic, available at www.jneurosci.org as supplemental material). Motor axons originating from this region of the spinal cord enter the brachial plexus with most axons projecting laterally to innervate the forelimbs. However, axons that will become the phrenic nerve continue caudally through the thoracic cavity eventually contacting the diaphragm near the dorsoventral midpoint. At this initial contact point, the phrenic nerve branches into three primary trunks, with two branches extending across the muscle 
to innervate the ventral and dorsal diaphragm. Another axon bundle extends dorsally and medially to innervate the crus of the diaphragm. Short terminal branches from each nerve trunk synapse with the muscle forming the motor endplate band. Although the innervation pattern is not precisely identical, this process is very similar on both the right and left sides of the body.

In each of the B6.Unc5c $c^{-/-}$embryos examined $(n>25)$, the motor innervation pattern was severely abnormal with typically $30-75 \%$ of the muscle uninnervated (Fig. 5A,B). Regions of the diaphragm regions lacking innervation were never observed in $U n c 5 c^{+/-}$or $U n c 5 c^{+/+}$littermates. Although all B6.Unc5 $c^{-/-}$embryos had large regions of the unninervated diaphragm, the exact presentation was variable and ranged from a complete lack of innervation (as visualized from the lack of both nerve and endplate staining) on either the left or the right side of the diaphragm, to a partial lack of innervation on both sides of the muscle. As in the trochlear nerve, whether the left side, the right side, or both sides were affected appeared stochastic. Clustering of synaptic proteins occurred on the innervated diaphragm, suggesting axons that reach the muscle form synaptic contacts. This is consistent with the apparently normal movements of mutant neonatal mice, which suggest many neuromuscular synapses are functional. However, the reduced number of axons in the mutant phrenic nerve resulted in a compensatory denser pattern of innervation than in control mice (Fig. $5 C, D)$. In contrast to the diaphragm, motor innervation of the intercostal muscles of the ribcage, also involved in respiration, appeared normal in $U n c 5 c^{-/-}$embryos (supplemental Fig. S2, available at www.j-

neurosci.org as supplemental material). Interestingly, sensory neuron innervation around the lateral edge of the diaphragm also appears relatively normal, although the sensory projections extend slightly more medially in muscle regions lacking motor innervation (Fig. $5 A, B$, asterisks).

Proximal to its point of contact with the muscle, the diameter of the phrenic nerve was markedly reduced, suggesting it contained fewer axons than the wild-type nerve. This was evident by immunofluorescence analysis with anti-neurofilament antibody (Fig. $6 A-C^{\prime}$ ), and the decrease in nerve caliber qualitatively correlated with the severity of diaphragm innervation defects. Axon counts in the mutant animals were significantly reduced compared with wild-type and heterozygous controls $(p<0.05$; twotailed $t$ test), as shown by transmission electron microscopic analysis of phrenic nerves (Fig. 6D-F, Table 3). The bilateral asymmetry of nerve defects in B6.Unc $5 c^{-1-}$ mice was reflected in the variable axon numbers from left and right nerves, as shown in Table 3 .

The state of postsynaptic differentiation and AChR clustering in the uninnervated portions of the E18.5 diaphragm are consistent with muscle that has never been contacted by a motor nerve (Lin et al., 2001; Yang et al., 2001). Furthermore, histological examination of the uninnervated muscle demonstrated normal muscle layering and thickness, suggesting there is no defect in myogenesis (data not shown). Finally, the aneural clustering of AChRs suggests the muscle is fully differentiated, because these clusters depend on expression of MuSK, a gene with expression that is induced in differentiated myotubes (Valenzuela et al., 1995). Thus, phrenic axonal-guidance phenotypes do not appear secondary to defects in muscle differentiation.

Diaphragm innervation defects in B6.Unc5c mutant mice could be attributable to either motor axon-pathfinding defects during early motor development or defects in the stabilization of neuromuscular synapses that could lead to secondary loss of phrenic nerve/muscle contact, as observed in mice defective for Erbb2 (Morris et al., 1999; Lin et al., 2000). To differentiate between these possibilities, diaphragms were isolated at E13.5, shortly after the phrenic nerve normally contacts the diaphragm, 

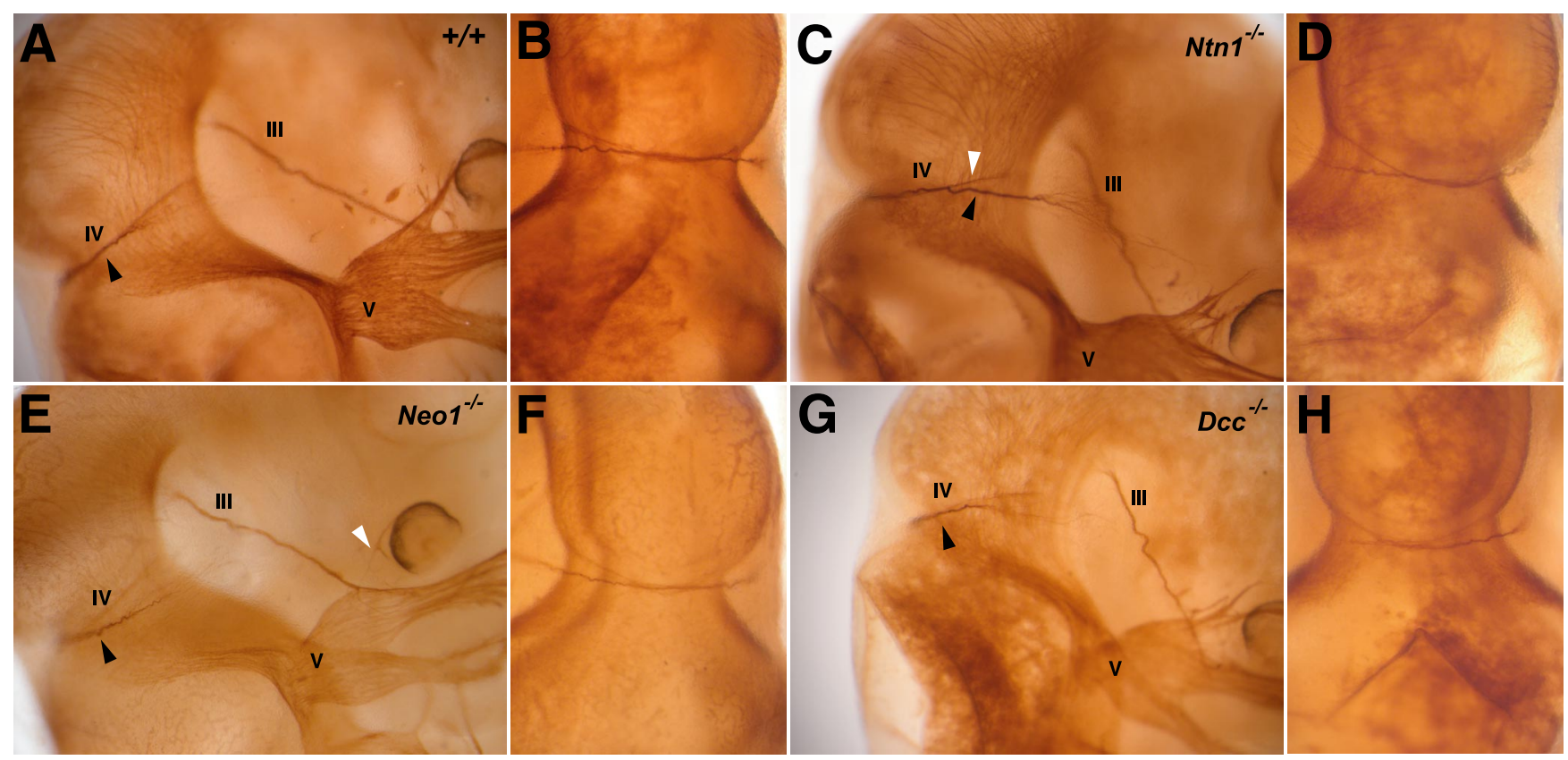

Figure 4. Normal trochlear projections in mice with other netrin signaling mutations. $A-D$, The trochlear nerve (IV) was visualized by whole-mount anti-neurofilament staining at E11.5 in control $(\boldsymbol{A}, \boldsymbol{B})$ and $\mathrm{Ntn}^{-/-}(\boldsymbol{C}, \boldsymbol{D})$ mice. The trochlear nerve arose from the dorsal isthmus and projected contralaterally as it should (black arrowheads). Although this had been reported previously for $\mathrm{Ntn} 1^{-/-}$mice, we confirmed the phenotype in C57BL/6 congenic mutant embryos. Note that the white arrowhead in $C$ is the deeper, ipsilateral nerve making its initial dorsal projection; this is visible as an out-of-focus shadow in several images but is most clearly seen here. $\boldsymbol{E}-\boldsymbol{H}$, Normal trochlear projections were also seen in B6 congenic mice homozygous for mutations in neogenin 1 $\left(\operatorname{Neo1}^{-/-} ; \boldsymbol{E}, \boldsymbol{F}\right)$ and $D c \boldsymbol{C}(\boldsymbol{G}, \boldsymbol{H})$. Interestingly, the ophthalmic branch of the trigeminal nerve is diminished or absent bilaterally in the Neo $1^{-/-}$mice (white arrowhead; $\boldsymbol{E}$ ), although other defects were not observed. In each case, the right side and dorsal views of the same embryo are shown. The left side of each embryo was also examined, and no trochlear nerve defects were seen (data not shown). The control embryo shown $(\boldsymbol{A}, \boldsymbol{B})$ is a wild-type littermate of the $N \operatorname{tn} 1^{-1-}$ embryo.

and axons were visualized by direct fluorescence of transgenic expression of EYFP in motor neurons (Fig. 7). Abnormalities in diaphragm innervation, similar to those observed in E18.5 $U n c 5 c^{-1-}$ embryos, were also observed in mutant embryos at E13.5. Thus, it is likely that phrenic axons fail to reach the diaphragm, rather than retracting after contact with the muscle.

In the trochlear nerve, we determined that the axons were misprojecting ventrally and ipsilaterally from the CNS. To determine where motor axons projections are disrupted in B6.Unc5c mutant embryos, we used the B6.Unc5 $\mathrm{c}^{-/-}$; Thy1-YFP16 mice to visualize motor neuron cell bodies and axons at early stages of development. Fluorescence stereomicroscope visualization of dissected E13.5 embryos did not reveal straying axons between the brachial plexus and the diaphragm in Unc5c mutant embryos, indicating that there is not a gross defect in the fasciculation of the nerve distal to the brachial plexus (data not shown). Nor were obviously misprojecting axons seen in the ventral horn of the cervical spinal cord at E13. Similarly, the ventral roots exiting the cervical spinal cord did not show evidence of defasciculation (supplemental Fig. S3, available at www.jneurosci.org as supplemental material). Thus, the trajectory(s) that this subset of motor axons takes in $U n c 5 c^{-1-}$ embryos is unclear. Based on our observations of the trochlear nerve, we would predict they misproject from the CNS, possibly fasciculating with other motor axons unrelated to the phrenic nerve.

\section{Other netrin signaling components do not affect phrenic nerve development}

Although disruption of netrin 1 and its receptors, DCC and neogenin, cause perinatal death (Serafini et al., 1996; Fazeli et al., 1997; Srinivasan et al., 2003), a role in the guidance of motor axons has not been reported previously for these molecules, and no effects of these mutations on trochlear axon guidance were observed. Similarly, these genes did not alter the guidance of the trochlear nerve, even in B6 congenic animals. To determine whether other netrin receptors may also be involved in phrenic motor axon guidance, we examined the expression of $U n c 5 c, D c c$, and Neo1 in the embryonic cervical spinal cord by in situ hybridization. Although these genes have distinct expression patterns in the developing spinal cord, $U n c 5 c, D c c$, and Neol transcripts were all detected in Chat-positive motor neurons of the ventral horn of the spinal cord (supplemental Fig. S4, available at www.jneurosci.org as supplemental material).

The expression patterns of $\mathrm{Dcc}$ and $\mathrm{Neo} 1$ were consistent with a potential role in phrenic motor axon guidance. The phrenic nerve was of normal caliber, and the diaphragm was fully innervated, with no unusual routing of the axons in B6.Dcc ${ }^{-1}$ or B6.Neo $1^{-1-}$ mutant embryos ( $n=8$ and $n=5$, respectively) (Fig. $8 B, C)$. In addition, we also examined the phenotype of mice deficient for the Ntn1 gene (Fig. 8D). Like Dcc and Neol mutant embryos, B6.Ntn1 ${ }^{-/-}$embryos did not show an altered pattern of motor innervation in the diaphragm $(n=9)$ (Fig. $8 D)$, demonstrating that, as in guidance of trochlear motor axons, these genes are not essential for phrenic nerve innervation of the diaphragm.

\section{SJL mice carry a suppressor of the diaphragm phenotype on Chromosome 17}

The complete penetrance of trochlear misprojections and diaphragm innervation defects in Unc5c mutant embryos on the B6 background, and attenuation of these defects in the original mixed B6/SJL hybrid background, suggested the presence of strain-specific loci that modify netrin signaling during axon outgrowth. Because the trochlear nerve is best examined in E11-E13 mice and the phrenic nerve is best examined during late embry- 
ogenesis, it is difficult to characterize both phenotypes in a single embryo. Thus, we chose to examine the diaphragm innervation phenotype for a modifier screen, because it is more likely to contribute to the lethality of the mice.

To examine the effect of genetic background on phrenic nerve development, we analyzed diaphragms from F2 B6;SJL$U n c 5 c^{-/-}$embryos. Mice heterozygous for the $U n c 5 c$ mutation from a B6 congenic colony were mated to SJL mice to create F1 Unc5c $c^{+/-}$mice. E18.5 embryos were obtained from timed matings of F1 heterozygous mice, of which 23\% (50 of 217) were homozygous for the Unc5c mutation. Three classes of diaphragm phenotypes were noted among $U n c 5 c^{-1-}$ embryos. Twelve of the 50 Unc $5 c^{-1-}$ embryos (24\%) had diaphragm defects as severe as those seen in B6.Unc5c ${ }^{-1-}$ embryos, with large regions $(30-75 \%)$ of the uninnervated diaphragm and a marked decrease in the caliber of the phrenic nerve (Fig. 9A). Conversely, 23 (46\%) of the mutant embryos had no discernable defects in diaphragm innervation and were indistinguishable from controls (Fig. 9B). Diaphragms from the remaining 15 mice (30\%) had an intermediate phenotype with small (10-20\%) regions of uninnervated muscle (Fig. 9C). These results suggest that introgression of the $\mathrm{B} 6$ background genetically predisposes $U n c 5 c^{-/-}$ embryos to defects in phrenic nerve development and further suggest that SJLderived loci can suppress these defects in mutant embryos.

To identify the chromosomal location of modifier loci, a genome scan was performed on DNA from the $50 \mathrm{~F} 2 \mathrm{Unc} 5 \mathrm{c}^{-/-}$ embryos (Fig. 9D). Genomic DNA from individual embryos was analyzed with 70 microsatellite markers polymorphic between B6 and SJL and distributed at $\sim 15-20 \mathrm{cM}$ intervals across the genome. Genome-wide significance thresholds were determined by permutation testing. Significant linkage (LOD, > 5.77; $p<0.01)$ was observed on proximal Chromosome 17 at D17Mit16. LOD scores for markers on other chromosomes were not significant $(p>0.05)$. Analysis of $U n c 5 c^{-1-}$ embryos with additional Chromosome 17 microsatellite markers (Fig. 9E) revealed a peak LOD score at D17Mit16 $(7.7 \mathrm{cM})$ with lower scores at flanking markers.

Examination of individual embryos revealed that embryos with severely disrupted diaphragm innervation most often had the B6/B6 genotype at the D17Mit16 locus (75\%; 9 of 12), whereas the genotype of unaffected embryos was skewed toward SJL/SJL or SJL/B6 $(96 \% ; 22$ of 23). These results significantly deviate from the expected Mendelian genotype ratio of 1:2:1 $\left(\chi^{2}\right.$ $=15.25 ; p>0.004)$ and are consistent with our hypothesis that a dominant, SJL-derived locus on Chromosome 17 mitigates the B6.Unc5c phrenic nerve phenotype. D17Mit16 genotypes of the 13 intermediate embryos appeared more random (5 B6/B6, 6
B6/SJL, 2 SJL/SJL), suggesting that SJL-mediated suppression of this phenotype is not complete and may involve complex interactions with additional modifier loci on other chromosomes.

\section{Discussion}

We demonstrate that $U n c 5 c$ mutant embryos on the B6 background have fully penetrant abnormalities in both cranial and spinal motor axon development, defects not previously associated with disruption of vertebrate netrin signaling. In particular, UNC5C is essential for proper projection of the trochlear nerve and proper diaphragm innervation by the phrenic nerve. Unc $5 c$ is clearly necessary for trochlear nerve guidance, as demonstrated by misprojection of axons that results in an aberrant CNS exit point. However, the exact nature of the phrenic nerve defects is less clear. Before the contact with the diaphragm, a striking reduction in the number of phrenic axons is observed. We did not observe defects in $U n c 5 c^{-l-}$ motor axons as they leave the ventral horn of the cervical spinal cord or defasciulation of the ventral roots, suggesting that, instead, mutant phrenic axons may defa- 

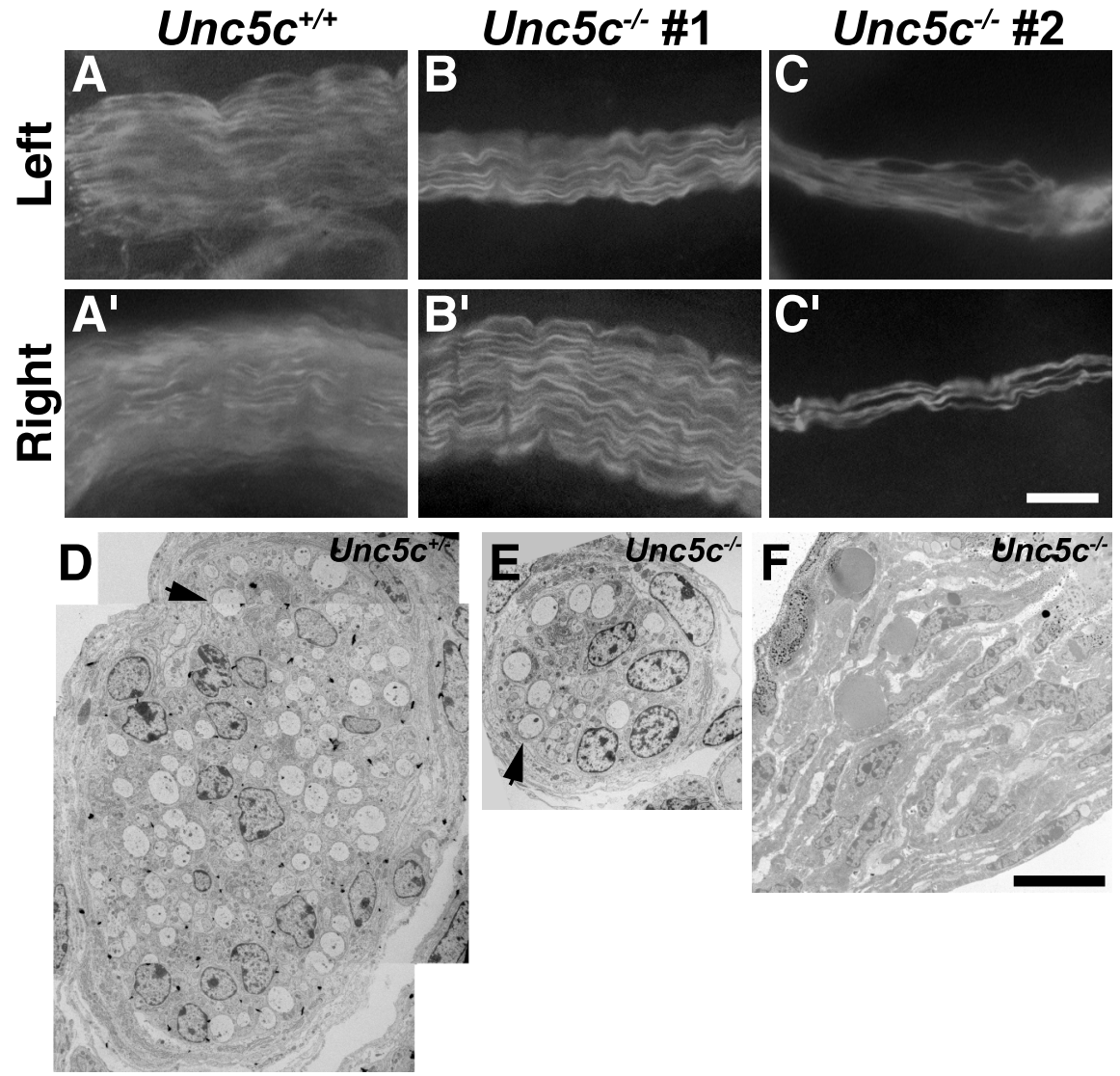

Figure 6. Decreased axon number in B6.Unc5 $\boldsymbol{c}^{-1-}$ phrenic nerves. $\boldsymbol{A}-\boldsymbol{C}^{\prime}$, The presentation of the motor innervation phenotype is highly variable in its symmetry, as shown by images of left $(\boldsymbol{A}-\boldsymbol{C})$ and right $\left(\boldsymbol{A}^{\prime}-\boldsymbol{C}^{\prime}\right)$ phrenic nerves immunostained with antibodies to neurofilament from E18.5 wild-type embryos $\left(\boldsymbol{A}, \boldsymbol{A}^{\prime}\right)$ and $\operatorname{Unc5c^{-1-}}$ embryos $\left(\boldsymbol{B}, \boldsymbol{B}^{\prime}, \boldsymbol{C}, \boldsymbol{C}^{\prime}\right)$. D-F, Note that in individual mutant animals, the left and right nerves varied considerably in caliber but were consistently smaller than controls. TEM images of right phrenic nerves from a heterozygous control $(\boldsymbol{D})$, a markedly affected mutant $(\boldsymbol{E})$, and a mutant that completely lacked a nerve $(\boldsymbol{F})$ are shown. Axons were defined as pale, circular profiles that were electron transparent in TEM with crosssectioned cytoskeletal filaments (arrowheads; $\boldsymbol{D}, \boldsymbol{E}$ ). $\boldsymbol{D}$ is a montage of two $5000 \times \mathrm{TEM}$ fields to show the entire nerve. Scale bars: $\boldsymbol{A}-\boldsymbol{C}^{\prime}, 18 \mu \mathrm{m} ; \boldsymbol{D}-\boldsymbol{F}, 8 \mu \mathrm{m}$.

Table 3. Axon deficiencies in B6.Unc5 $\mathrm{C}^{-1-}$ phrenic nerves

\begin{tabular}{lcl}
\hline Genotype & Left nerve (axons) & Right nerve (axons) \\
\hline$+/+$ & $88.2 \pm 5.6(n=5)$ & $83.0 \pm 6.9(n=9)$ \\
$+/-$ & $82.2 \pm 10.8(n=5)$ & $86.3 \pm 10.5(n=4)$ \\
$-I-\# 1$ & 7 & 22 \\
$-I-\# 2$ & ND & 67 \\
$-I-\# 3$ & 63 & 0 \\
$-I-\# 4$ & 9 & 16 \\
$-I-\# 5$ & 12 & ND \\
\hline
\end{tabular}

Right and left phrenic nerves from E18.5 embryos were plastic embedded and cross sectioned. Axons, as distinguished by their round, pale profiles containing cytoskeletal filaments, were counted in toluidine blue-stained sections or in thin sections by transmission electron microscopy. ND, Not determined.

siculate from the motor axon bundle distal to the ventral root, but before the brachial plexus. Alternatively, phrenic axons in mutant embryos may fail to navigate choice points associated with the turn at the brachial plexus, where most axons extend laterally to innervate the limb and only a small portion continue caudally through the thoracic cavity eventually contacting the diaphragm. Finally, it is possible that the phrenic nerve defect is attributable to abnormalities in differentiation or migration of phrenic motor neurons. However, the small number of axons that comprise the phrenic nerve, the lack of specific markers for these axons and/or the motor neurons from which they arise, and the stochastic laterality of the motor axon defects make it difficult to precisely determine the exact location of these defects in $U n c 5 c$ mutant embryos.

UNC5 receptors can serve as the netrin coreceptor with UNC40 receptors when expressed ectopically, mediating longrange repulsion of axons from netrin sources (Hong et al., 1999; Keleman and Dickson, 2001). Although the Neo1 mutation appears to specifically disrupt the ophthalmic branch of the trigeminal nerve, a sensory projection that innervates the skin and deeper tissues including the dura mater, we demonstrate that the trochlear and phrenic nerves are normal in embryos homozygous for mutations in the vertebrate homologs of the unc-40 family, even when these mutations are placed on the B6 background. Both Dcc and Neol are expressed in the developing spinal motor column and on motor axons (supplemental Fig. S4, available at www. jneurosci.org as supplemental material) (Keino Masu et al., 1996). However, determination of whether phrenic motor neurons coexpress the UNC-5- and UNC-40related receptors awaits the development of markers for this subset of motor neurons. Coexpression of DCC and Neol would suggest that these family members might be functionally redundant in this pathway. The results of this analysis will be particularly interesting, given recent findings that suggest Drosophila motor axon guidance phenotypes that are dependent on Unc-5 but not the DCC homolog frazzled, or vice versa, may be attributable to transcriptional regulation of different receptor combinations (Labrador et al., 2005).

The ventral rather than dorsal projection of the trochlear nerve in $U n c 5 c^{-/-}$embryos is consistent with in vitro data indicating that the outgrowth of these axons is repelled by netrin 1 (Colamarino and Tessier-Lavigne, 1995; Shirasaki et al., 1996; Varela-Echavarria et al., 1997). In wild-type embryos, these axons project dorsally and extend toward and across the midbrainhindbrain boundary, crossing the midline and finally exiting the CNS dorsally to innervate the contralateral superior oblique muscle of the eye. Although defective trochlear nerves were observed in every mutant embryo examined, these projections are variable. In some cases, the nerve was missing. In other embryos, nerves entirely projected in the rostroventral direction, whereas in the remaining embryos, nerves have two apparently independent projections, one defective and one normal. These bifurcating projections may reflect independent guidance mechanisms for the axons arising from the midbrain trochlear neurons and those axons with cell bodies that are located in rhombomere 1 (Irving et al., 2002). Alternatively, these projections could be attributable to defasculation of later-migrating axons from the pioneer axons. In any case, axons with defective trajectories still reach the eye, suggesting that these axons retain intrinsic target recognition capability.

Although the initial dorsal migration of trochlear axons is thought to rely on chemorepellents, we cannot rule out the pos- 

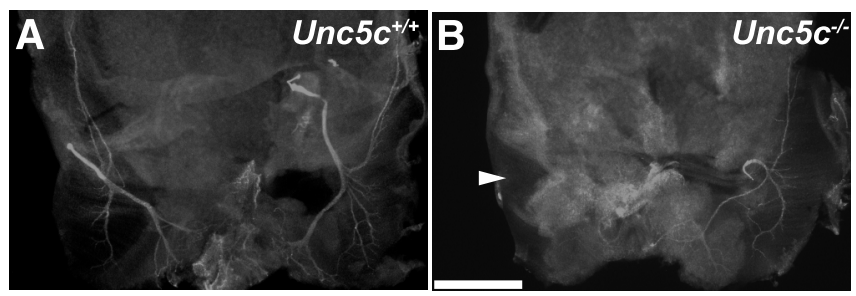

Figure 7. Defects in phrenic innervation of $\mathrm{E} 13.5 \mathrm{Unc} 5 \mathrm{C}^{-/-}$diaphragms. $\boldsymbol{A}$, The phrenic nerve fails to form in $U n \mathrm{CC}^{-1-}$ mice, rather than extending and subsequently retracting. The nerve contacts the muscle during day 12 of gestation and has elaborated over the developing muscle by E13.5 in control mice. $\boldsymbol{B}$, The lack of innervation of the diaphragm is readily apparent by E13.5 in UnC5 ${ }^{-1-}$ mice (arrowhead). In this example, the left nerve has completely failed to contact the muscle (ventral is up). Axons were visualized by crossing a transgenic reporter line expressing EYFP in all motor neurons (B6.Thy1-YFP16) onto the B6.Unc5 $\mathrm{C}^{-1-}$ background, and YFP-positive axons of the phrenic nerve were viewed by direct fluorescence. Scale bar, $550 \mu \mathrm{m}$.
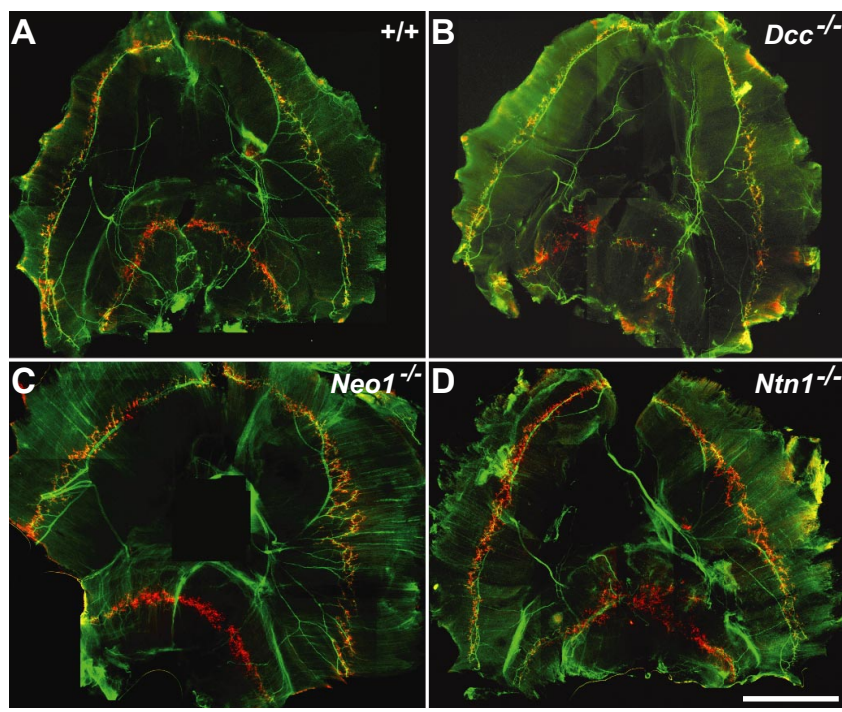

Figure 8. Diaphragm innervation in Dcc, Neo1, and Ntn1 mutant animals. At E18.5 to P0, the diaphragms of control $(\boldsymbol{A}), \mathrm{DCC}^{-1-}(\boldsymbol{B}), \mathrm{NeO}^{-/-}(\boldsymbol{C})$, and $N \operatorname{tn} 1^{-/-}(\boldsymbol{D})$ mice were stained with neurofilament antibodies and $\alpha$-bungarotoxin to visualize nerve (green) and AChRs (red), respectively. Montages of fluorescence micrographs are shown. No lack of innervation was seen in any of the mutants. All mutations were backcrossed into a $57 \mathrm{BL} / 6 \mathrm{~J}$ background before analysis. The control mouse is a $+/+$ littermate of the $\mathrm{Dcc}^{-/-}$. Ventral is down, and right is to the right. Scale bar, $1.4 \mathrm{~mm}$.

sibility that $U n c 5 c^{-/-}$trochlear axons fail to respond to an attractant expressed by the isthmic organizer of the midbrain/hindbrain, a region shown to attract trochlear axons in vitro (Irving et al., 2002). The abnormal migration of cerebellar granule cells into this region in $U n c 5 c^{-1-}$ mice suggests that the UNC5C receptor responds to cues expressed in this region (Ackerman et al., 1997; Przyborski et al., 1998). A role for UNC5C in axon attraction is consistent with our findings that a major subset of CST axons in the $U n c 5 c^{-1-}$ mouse fail to cross the midline (Finger et al., 2002). Similarly, nonallelic noncomplementation was observed between the $U n c 5 c$ and $D c c$ null mutations, suggesting that these molecules may be partially redundant in mediating either attraction or repulsion of CST guidance at the midline.

Whether the netrins are necessary for UNC5C-mediated guidance of the trochlear and phrenic nerve is unclear. We, and others (Colamarino and Tessier-Lavigne, 1995), have demonstrated that netrin 1 is dispensable for the guidance of trochlear (and phrenic) motor axons. This result is in contrast to the phenotypes of C. elegans unc-5 mutants that consistently overlap with phenotypes of the mutations in the netrin-encoding unc- 6 gene (Hedgecock et al., 1990). Like the trochlear defect, cerebellar neuronal migration defects (Bloch-Gallego et al., 1999; J. H. Finger and S. L. Ackerman, unpublished observation) and some CST abnormalities (Finger et al., 2002) observed in $U n c 5 c^{-1-}$ mice are also netrin 1 independent. Furthermore, the lack of phrenic axon defects in $\mathrm{Ntn1}^{-/-}$embryos is consistent with results from in vitro experiments analyzing axonal outgrowth in rat embryo tissue explants cocultured with cells expressing netrin1 (VarelaEchavarria et al., 1997).

Although netrin 1 is the best characterized netrin family member in mammals, other netrin family members exist, including the closely related netrin3 (Puschel, 1999; Wang et al., 1999) and netrin4 ( $\beta$-netrin) (Koch et al., 2000; Yin et al., 2000). Formally, any of these ligands could be sufficient or redundant with netrin 1 in signaling to UNC5C in migrating motor axons, but netrin3, which has both axonal outgrowth and repellent activities, has a high affinity to the vertebrate UNC receptors (Wang et al., 1999). Netrin 3 is expressed in both motor and sensory neurons and their axons in the embryonic mouse spinal cord and by developing myoblasts in the embryo, suggesting it may play a role in guiding peripheral motor axons to their muscle targets (Wang et al., 1999; Seaman and Cooper, 2001).

Interestingly, the netrin 3 gene is located on proximal Chromosome 17 (Wang et al., 1999) near the genomic region we have identified as having a major influence on Unc5c-mediated phrenic nerve guidance, making netrin 3 a candidate for the modulator of the Unc5c phrenic axon phenotype. Quantitative RTPCR failed to reveal differences in mRNA expression levels from the spinal cord and hindquarter muscle in C57BL/6J and SJL embryos, but two nucleotide changes predicted to alter amino acids were found: leucine 23 is changed to proline, and valine 215 is changed to methionine in SJL, but whether these changes affect function of this ligand is not known.

Although netrin3 is an interesting candidate for a modifier of this phenotype, it is important to remember that the $\mathrm{rcm}$ mutation is a null allele for $U n c 5 c$. Thus, changes in receptor signaling efficacy, such as that associated with the clr-1 protein tyrosine phosphatase in C. elegans, are not mechanistically possible (Chang et al., 2004). Therefore, we anticipate that the modifier locus we have identified will be a component of a partially redundant or parallel signaling pathway, which differs in function or expression between B6 and SJL. Although netrin3, or any other modifier gene, could be influencing the signaling of other netrin receptors, it is also possible that components of another signaling pathway, such as the neuropilin-semaphorin III/D pathway, which has been shown to act as a chemorepulsive signal for this nerve (Chen et al., 2000; Giger et al., 2000; Sahay et al., 2003; Watanabe et al., 2004), are disrupted in B6 mice.

Finally, although the trochlear nerve defects in Unc5c mutant embryos can be also rescued by the SJL genetic background, we do not know whether the same modifier locus influences the trochlear nerve. The generation of B6 congenic mice carrying the identified portion of Chromosome 17 from SJL will allow analysis of the contribution of this region to the suppression of both the trochlear and phrenic axon defects in $U n c 5 c^{-1-}$ embryos.

Our results demonstrate that genetic background has a profound impact on neonatal survival and motor axon guidance in Unc5c mutant mice. Genetic screens of mutagenized C. elegans have identified several loci that suppress unc5-dependent dorsal migrations in touch neurons ectopically expressing UNC5 (Colavita and Culotti, 1998). The strain dependence of the Unc5c phrenic nerve phenotype indicates that modifier loci also exist in 

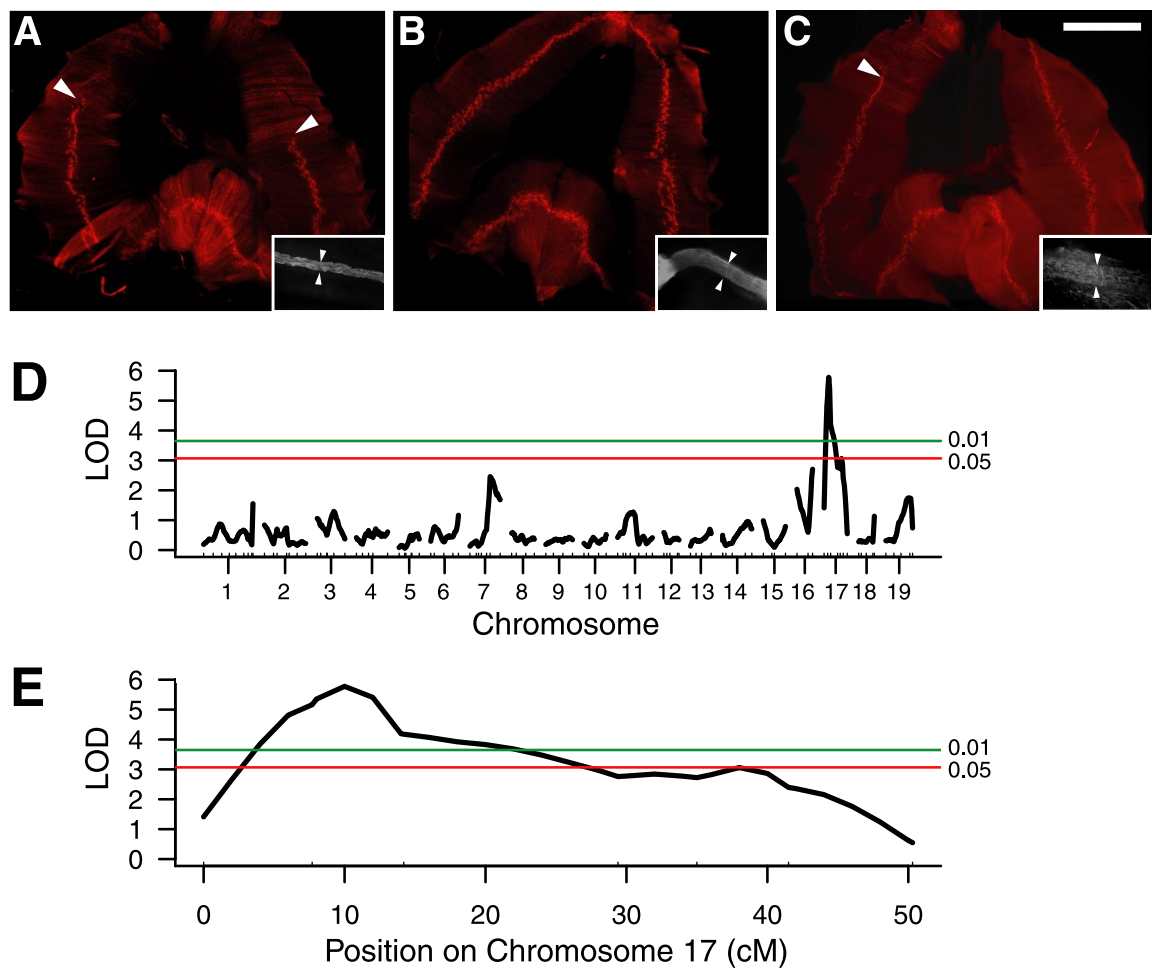

Figure 9. Mapping of modifier loci of phrenic nerve defects in Unc $5 \mathrm{C}^{-/-}$embryos. Phrenic nerve innervation of E18.5 diaphragms from $\mathrm{F} 2$ UnC5C ${ }^{-/-}$embryos on a segregating $\mathrm{B} 6 / \mathrm{SJL}$ genetic background is variable. $\boldsymbol{A}, \boldsymbol{B}$, Twenty-four percent of Unc $5 \mathrm{C}^{-1-}$ had innervation defects as severe as those seen in Unc5 $\mathrm{C}^{-1-}$ on the $(57 \mathrm{BL} / 6 \mathrm{~J}$ background $(\boldsymbol{A})$, whereas $46 \%$ had no discernable defects $(\boldsymbol{B})$. $\boldsymbol{C}$, Many embryos (30\%) also showed an intermediate phenotype with innervation defects in a small portion of the diaphragm, most often the ventralmost region (at the top of the figure). Arrowheads denote the boundary of the innervation. The classifications of severe, mild, and unaffected were based on whole-mount diaphragm staining for AChRs (red) on the muscle denoting the endplate band, as shown in $\boldsymbol{A}-\boldsymbol{C}$. The caliber of the phrenic nerve innervating each muscle (insets) covaried with the extent of innervation. Arrowheads denote the thickness of each nerve; the right phrenic nerve for each muscle is shown. These results suggest that $S \mathrm{JL}$ carries a dominant supressor of the $\mathrm{B} 6 . U n \mathrm{CS}^{-/-}$phrenic nerve phenotype; however, the presence of the intermediate class of mutants suggests possible polygenic influences. Scale bar, $1.5 \mathrm{~mm}$. Insets, are $220 \times 145$ $\mu \mathrm{m}$. To identify the chromosomal location of main-effect loci affecting phrenic nerve development in Unc $5 \mathrm{C}^{-1-}$ mice, a genome scan was performed on $\mathrm{F} 2 \mathrm{~B} 6 / \mathrm{SJL}$ Unc $5 \mathrm{C}^{-1-}$ mice using 70 microsatellite markers. $\boldsymbol{D}$, Chromosomes $1-19$ are represented on the $x$-axis with spacing representing map distance. Genome-wide significance thresholds of 0.05 and 0.01 are shown by red and green lines, respectively $(\boldsymbol{D}, \boldsymbol{E})$. Note significant linkage on Chromosome $17(\mathrm{LOD},>5.77 ; p<0.01)$. LOD scores for markers on other chromosomes were not significant ( $p>0.05)$. E, A closer examination of Chromosome 17 using additional markers demonstrating the peak LOD score occurs on proximal Chromosome 17 at D17Mit16 (7.7 cM). The distance along the chromosome is shown on the $x$-axis in centimorgans. The microsatellite markers tested were D17Mit245 (0 cM), D17Mit16 (7.7 cM), D17Mit51 (14.2 cM), D17Mit88 (29.4 cM), D17Mit205 (35 cM) D17Mit187 (41.5 cM), and D17Mit123 (50.3 cM).

vertebrates, with a major dominant locus influencing phrenic motor axon guidance on proximal Chromosome 17. The identification of such modifier loci will be a powerful way to isolate genes that modulate or interact with UNC5C/netrin signaling in motor axons.

\section{References}

Ackerman SL, Kozak LP, Przyborski SA, Rund LA, Boyer BB, Knowles BB (1997) The mouse rostral cerebellar malformation gene encodes an UNC-5-like protein. Nature 386:838-842.

Barallobre MJ, Pascual M, Del Rio JA, Soriano E (2005) The netrin family of guidance factors: emphasis on netrin-1 signalling. Brain Res Brain Res Rev 49:22-47.

Bloch-Gallego E, Ezan F, Tessier-Lavigne M, Sotelo C (1999) Floor plate and netrin- 1 are involved in the migration and survival of inferior olivary neurons. J Neurosci 19:4407-4420.

Broman KW, Wu H, Sen S, Churchill GA (2003) R/qtl: QTL mapping in experimental crosses. Bioinformatics 19:889-890.

Burgess RW, Peterson KA, Johnson MJ, Roix JJ, Welsh IC, O’Brien TP (2004) Evidence for a conserved function in synapse formation reveals
$\mathrm{Phr} 1$ as a candidate gene for respiratory failure in newborn mice. Mol Cell Biol 24:1096-1105.

Chan SS, Zheng H, Su MW, Wilk R, Killeen MT, Hedgecock EM, Culotti JG (1996) UNC-40, a C. elegans homolog of DCC (Deleted in colorectal cancer), is required in motile cells responding to UNC-6 netrin cues. Cell 87:187-195.

Chang C, Yu TW, Bargmann CI, Tessier-Lavigne M (2004) Inhibition of netrin-mediated axon attraction by a receptor protein tyrosine phosphatase. Science 305:103-106.

Chen H, Bagri A, Zupicich JA, Zou Y, Stoeckli E, Pleasure SJ, Lowenstein DH, Skarnes WC, Chédotal A, Tessier-Lavigne M (2000) Neuropilin-2 regulates the development of selective cranial and sensory nerves and hippocampal mossy fiber projections. Neuron 25:43-56.

Churchill GA, Doerge RW (1994) Empirical threshold values for quantitative trait mapping. Genetics 138:963-971.

Colamarino SA, Tessier-Lavigne M (1995) The axonal chemoattractant netrin-1 is also a chemorepellent for trochlear motor axons. Cell 81:621-629.

Colavita A, Culotti JG (1998) Suppressors of ectopic UNC-5 growth cone steering identify eight genes involved in axon guidance in $\mathrm{Cae}$ norhabditis elegans. Dev Biol 194:72-85.

Coppola E, Pattyn A, Guthrie SC, Goridis C, Studer M (2005) Reciprocal gene replacements reveal unique functions for Phox2 genes during neural differentiation. EMBO J 24:4392-4403.

Fazeli A, Dickinson SL, Hermiston ML, Tighe RV, Steen RG, Small CG, Stoeckli ET, Keino-Masu K, Masu M, Rayburn H, Simons J, Bronson RT, Gordon JI, Tessier-Lavigne M, Weinberg RA (1997) Phenotype of mice lacking functional Deleted in colorectal cancer (Dcc) gene. Nature 386:796-804.

Feng G, Mellor RH, Bernstein M, Keller-Peck C, Nguyen QT, Wallace M, Nerbonne JM, Lichtman JW, Sanes JR (2000) Imaging neuronal subsets in transgenic mice expressing multiple spectral variants of GFP. Neuron 28:41-51.

Finger JH, Bronson RT, Harris B, Johnson K, Przyborski SA, Ackerman SL (2002) The netrin 1 receptors Unc5h3 and Dcc are necessary at multiple choice points for the guidance of corticospinal tract axons. J Neurosci 22:10346-10356.

Gautam M, Noakes PG, Moscoso L, Rupp F, Scheller RH, Merlie JP, Sanes JR (1996) Defective neuromuscular synaptogenesis in agrin-deficient mutant mice. Cell 85:525-535.

Giger RJ, Cloutier JF, Sahay A, Prinjha RK, Levengood DV, Moore SE, Pickering S, Simmons D, Rastan S, Walsh FS, Kolodkin AL, Ginty DD, Geppert M (2000) Neuropilin-2 is required in vivo for selective axon guidance responses to secreted semaphorins. Neuron 25:29-41.

Goldowitz D, Hamre KM, Przyborski SA, Ackerman SL (2000) Granule cells and cerebellar boundaries: analysis of Unc5h3 mutant chimeras. J Neurosci 20:4129-4137.

Hedgecock EM, Culotti JG, Hall DH, Stern BD (1987) Genetics of cell and axon migrations in Caenorhabditis elegans. Development 100:365-382.

Hedgecock EM, Culotti JG, Hall DH (1990) The unc-5, unc-6, and unc-40 genes guide circumferential migrations of pioneer axons and mesodermal cells on the epidermis in C. elegans. Neuron 2:61-85.

Hong K, Hinck L, Nishiyama M, Poo MM, Tessier-Lavigne M, Stein E (1999) A ligand-gated association between cytoplasmic domains of UNC5 and DCC family receptors converts netrin-induced growth cone attraction to repulsion. Cell 97:927-941. 
Irving C, Malhas A, Guthrie S, Mason I (2002) Establishing the trochlear motor axon trajectory: role of the isthmic organiser and Fgf8. Development 129:5389-5398.

Keino Masu K, Masu M, Hinck L, Leonardo ED, Chan SS, Culotti JG, TessierLavigne M (1996) Deleted in colorectal cancer (DCC) encodes a netrin receptor. Cell 87:175-185.

Keleman K, Dickson BJ (2001) Short- and long-range repulsion by the Drosophila Unc5 netrin receptor. Neuron 32:605-617.

Kitsukawa T, Shimizu M, Sanbo M, Hirata T, Taniguchi M, Bekku Y, Yagi T, Fujisawa H (1997) Neuropilin-semaphorin III/D-mediated chemorepulsive signals play a crucial role in peripheral nerve projection in mice. Neuron 19:995-1005.

Koch M, Murrell JR, Hunter DD, Olson PF, Jin W, Keene DR, Brunken WJ, Burgeson RE (2000) A novel member of the netrin family, beta-netrin, shares homology with the beta chain of laminin: identification, expression, and functional characterization. J Cell Biol 151:221-234.

Kolodziej PA, Timpe LC, Mitchell KJ, Fried SR, Goodman CS, Jan LY, Jan YN (1996) Frazzled encodes a Drosophila member of the DCC immunoglobulin subfamily and is required for CNS and motor axon guidance. Cell 87:197-204.

Labrador JP, O'Keefe D, Yoshikawa S, McKinnon RD, Thomas JB, Bashaw GJ (2005) The homeobox transcription factor Even-skipped regulates Netrin-receptor expression to control dorsal motor-axon projections in Drosophila. Curr Biol 15:1413-1419.

Leighton PA, Mitchell KJ, Goodrich LV, Lu X, Pinson K, Scherz P, Skarnes WC, Tessier-Lavigne M (2001) Defining brain wiring patterns and mechanisms through gene trapping in mice. Nature 410:174-179.

Lin W, Sanchez HB, Deerinck T, Morris JK, Ellisman M, Lee KF (2000) Aberrant development of motor axons and neuromuscular synapses in erbB2-deficient mice. Proc Natl Acad Sci USA 97:1299-1304.

Lin W, Burgess RW, Dominguez B, Pfaff SL, Sanes JR, Lee KF (2001) Distinct roles of nerve and muscle in postsynaptic differentiation of the neuromuscular synapse. Nature 410:1057-1064.

Mitchell KJ, Doyle JL, Serafini T, Kennedy TE, Tessier-Lavigne M, Goodman CS, Dickson BJ (1996) Genetic analysis of Netrin genes in Drosophila: Netrins guide CNS commissural axons and peripheral motor axons. Neuron 17:203-215.

Mitchell KJ, Pinson KI, Kelly OG, Brennan J, Zupicich J, Scherz P, Leighton PA, Goodrich LV, Lu X, Avery BJ, Tate P, Dill K, Pangilinan E, Wakenight P, Tessier-Lavigne M, Skarnes WC (2001) Functional analysis of secreted and transmembrane proteins critical to mouse development. Nat Genet 28:241-249.

Morris JK, Lin W, Hauser C, Marchuk Y, Getman D, Lee KF (1999) Rescue of the cardiac defect in ErbB2 mutant mice reveals essential roles of ErbB2 in peripheral nervous system development. Neuron 23:273-283.

Pattyn A, Morin X, Cremer H, Goridis C, Brunet JF (1997) Expression and interactions of the two closely related homeobox genes Phox $2 \mathrm{a}$ and Phox2b during neurogenesis. Development 124:4065-4075.

Przyborski SA, Knowles BB, Ackerman SL (1998) Embryonic phenotype of Unc5h3 mutant mice suggests chemorepulsion during the formation of the rostral cerebellar boundary. Development 125:41-50.
Puschel AW (1999) Divergent properties of mouse netrins. Mech Dev 83:65-75.

Sahay A, Molliver ME, Ginty DD, Kolodkin AL (2003) Semaphorin 3F is critical for development of limbic system circuitry and is required in neurons for selective CNS axon guidance events. J Neurosci 23:6671-6680.

Sanes JR, Lichtman JW (2001) Induction, assembly, maturation and maintenance of a postsynaptic apparatus. Nat Rev Neurosci 2:791-805.

Schneider VA, Granato M (2003) Motor axon migration: a long way to go. Dev Biol 263:1-11.

Seaman C, Cooper HM (2001) Netrin-3 protein is localized to the axons of motor, sensory, and sympathetic neurons. Mech Dev 101:245-248.

Sen S, Churchill GA (2001) A statistical framework for quantitative trait mapping. Genetics 159:371-387.

Serafini T, Colamarino SA, Leonardo ED, Wang H, Beddington R, Skarnes WC, Tessier-Lavigne M (1996) Netrin-1 is required for commissural axon guidance in the developing vertebrate nervous system. Cell 87:1001-1014.

Shirasaki R, Mirzayan C, Tessier-Lavigne M, Murakami F (1996) Guidance of circumferentially growing axons by netrin-dependent and -independent floor plate chemotropism in the vertebrate brain. Neuron 17:1079-1088.

Srinivasan K, Strickland P, Valdes A, Shin GC, Hinck L (2003) Netrin-1/ neogenin interaction stabilizes multipotent progenitor cap cells during mammary gland morphogenesis. Dev Cell 4:371-382.

Valenzuela DM, Stitt TN, DiStefano PS, Rojas E, Mattsson K, Compton DL, Nunez L, Park JS, Stark JL, Gies DR, et al (1995) Receptor tyrosine kinase specific for the skeletal muscle lineage: expression in embryonic muscle, at the neuromuscular junction, and after injury. Neuron 15:573-584.

Varela-Echavarria A, Tucker A, Puschel AW, Guthrie S (1997) Motor axon subpopulations respond differentially to the chemorepellents netrin-1 and semaphorin D. Neuron 18:193-207.

Wadsworth WG, Hedgecock EM (1996) Hierarchical guidance cues in the developing nervous system of C. elegans. BioEssays 18:355-362.

Wadsworth WG, Bhatt H, Hedgecock EM (1996) Neuroglia and pioneer neurons express UNC-6 to provide global and local netrin cues for guiding migrations in C. elegans. Neuron 16:35-46.

Wang H, Copeland NG, Gilbert DJ, Jenkins NA, Tessier-Lavigne M (1999) Netrin-3, a mouse homolog of human NTN2L, is highly expressed in sensory ganglia and shows differential binding to netrin receptors. J Neurosci 19:4938-4947.

Watanabe Y, Toyoda R, Nakamura H (2004) Navigation of trochlear motor axons along the midbrain-hindbrain boundary by neuropilin 2 . Development 131:681-692.

Yang X, Arber S, William C, Li L, Tanabe Y, Jessell TM, Birchmeier C, Burden SJ (2001) Patterning of muscle acetylcholine receptor gene expression in the absence of motor innervation. Neuron 30:399-410.

Yin Y, Sanes JR, Miner JH (2000) Identification and expression of mouse netrin-4. Mech Dev 96:115-119. 